\title{
The Oxford Handbook of Latin American Christianity
}

Orique, David Thomas, Susan Fitzpatrick-Behrens, and Virginia Garrard, eds. The Oxford Handbook of Latin American Christianity. New York: Oxford University Press, 2020. 632 pp. \$150. Hardcover. ISBN: 978-0199860357.

The history of Christianity in Latin America is long and complex, spans a vast geography, is born from a diverse layering of cultures and international entanglements, and is made up of a large list of characters and events. Any work that attempts to encompass and explore the reality of Christianity in this context, in a way that does holistic justice to the material, has a daunting task to accomplish. Though not exhaustive by any means, this is what the Oxford Handbook of Latin American Christianity $(O H L A C)$ attempts, and it is generally successful. It is a tour for the academic inquirer of Latin American Christianity in one volume, without oversimplification. This means that the OHLAC is not a quick read or a popular summary, but it is a nuanced and useful resource for the serious student of religion.

The editors have selected a roster of authors who approach their subject matter with precision and care. In fact, there are times that the level of scholarly focus has produced some very specific and rather narrowly defined articles. For example, Matthew O’Hara's article, "Time and Christianity in Latin America," is a fascinating but surprisingly deep dive into conceptions of time amongst indigenous Nahua groups and Spanish missionaries in New Spain (Central Mexico) (23-38). He explicates how these conceptions were synthesized together into the Christianity of the colonial era. Coming across an article of such specificity early on in the OHLAC, one might wonder whether the forest gets lost in looking at the trees. However, when reading the articles presented as a collection, the landscape of Latin American Christianity does begin to unfold through these particular examinations because of the overlaps and interconnectedness of the articles. Each scholar adds his or her specialty to the mix while major themes like the development of inculturation/contextualization, missionary strategies, liberation theology, or the charismatic movement are covered from multiple angles in various articles.

Of course, Roman Catholicism is going to loom large in a volume on Latin American Christianity, and it is rightfully given a large amount of space. However, there are really two large gravity wells in the OHLAC between which most of the topics covered spin and spiral: Roman Catholicism and Pentecostalism. One provides the initial starting point and cultural stage for Latin American Christianity while the other is the dynamic movement which has most shifted and influenced the Roman Catholic religious hegemony in many Latin American countries in recent decades. Most articles inevitably swirl in and out of the pull of these two expressions of faith. On the whole, there is a fair balance here, but there were times I wished more space were given to minority or niche groups. That may be why I found the article of Lawson, Xydias, and Cragun on Mormons, Seventh-Day Adventists, and Jehovah's Witnesses in Latin America particularly memorable (411-34). Their comparison of the ways each group did missionary work in Latin America and their study of reasons for consistently underreporting or overreporting membership amongst these groups (contrasted with census data) was enlightening.

While all Latin American countries get a mention at some point, the editors do not seem concerned about giving equal time to every country. The more populated countries like Argentina, 
Brazil, and Mexico receive much attention. Although not as large, Guatemala, with its diversity of religious groups and the political/religious questions surrounding the civil war and evangelical dictator, Riós Montt, is the object of multiple discussions. For the reader looking for a guide into the religious history of countries like Bolivia, Paraguay, or Uruguay, though, this is not the place to find it.

The contributors and editors of the OHLAC have created a wide-ranging and detailed look at Christianity in Latin America. Articles provide close examinations of the phenomena of Latin American Christianity, as well as opening possibilities for further study. The writing tends to be sensitive and critical. While not written with the casual reader in mind, it is a useful reference work for the student of religion or Latin American history.

Zachariah Motts, MDiv

MLIS Student

Kent State University

Kent, $\mathrm{OH}$ 